Website: http://journal.umy.ac.id/index.php/mrs

DOI: $10.18196 / \mathrm{jmmr} .5116$.

\title{
Analisis Pelaksanaan Sertifikasi ISO 9001 : 2008 Puskesmas Kalasan Kabupaten Sleman
}

\author{
Khamidah Yuliati* \\ *Penulis Korespondensi:dr.yuli69@gmail.com \\ ${ }^{1}$ Puskesmas Kalasan Dinas Kesehatan Kabupaten Sleman \\ ${ }^{2}$ Magister Manajemen Rumah Sakit Universitas Muhammadiyah Yogyakarta

\begin{tabular}{l}
\hline INDEXIN G \\
\hline Keywords: \\
ISO 9001: 2008 \\
certification; \\
employee work- \\
satisfaction; \\
work environment and \\
service quality of Kalasan \\
Health Center.
\end{tabular}

\begin{abstract}
A B S TR A C T
The background of the study was the implementation of standardization of health service quality stated in ISO 9001: 2008 in Kalasan Health Center effectively applied on July 9th, 2009. It was hoped that the implementation of standardization of basic health service quality increase the quality of health service and human resources. The data collection was conducted by interview and questionnaire, and the collected data were in the form of primary and secondary data. The number of the research sample was 40 respondents. The data analysis method used was descriptive. The conclusions of the research result and analysis were (1) all employees increase the service quality for all patients in Kalasan Health Center. The curative aspect was emphasized on outpatients, and the stabilization of emergency and referral patients. (2) Acknowledging qualified work achievements by giving the opportunity to have position promotion as procedure assigned. Work satisfaction was from the existing of formation facility or space condition that gave comfort feeling. (3) Work team and colleague feeling needed to be maintained so that priority gap got decreased. The coordination between the employer and the employee is useful to finish the work. (4) The institution gave guarantee on health service quality which was as the hope of the consumer (patient) and strengthened the competitiveness. Therefore, the implementation of quality management system based on the concept of ISO 9001:2008 as the effort to strengthen the competitiveness was urgent.
\end{abstract}

C 2016 JMMR. All rights reserved

Article history: received 25 Jul 2016; revised 19 Okt 2016; accepted 25 Nov 2016

\section{PENDAHULUAN}

Puskesmas Kalasan Kabupaten Sleman tahun 2012, keberhasilan program Kesehatan yang dilaksanakan masih perlu ditingkatkan dan dibenahi secara lebih intensif lagi, hal ini disebabkan oleh: perencanaan dan pengarahan layanan kesehatan yang disusun Kepala Puskesmas perlu makin ditingkatkan, sistem manajemen belum mengatasi permasalahan yang timbul, pelaksanaan kegiatan cenderung rutin dan belum inovatif karena belum memperhatikan rencana yang telah dibuat, program yang mendapat perhatian hanya terfokus layanan rutin, program yang bersifat mengatasi dan pendeteksian pada program yang lain perlu ditingkatkan. Pengawasan pelaksanaan tugas di Puskesmas masih lemah, pengukuran pelaksanaan kegiatan perlu dilaksanakan lebih baik.

Fenomena tersebut dari sisi kinerja Puskesmas, diantaranya meliputi: (1) pemeriksaan karyawan sering dilaksanakan oleh tenaga paramedis terutama di Puskesmas Pembantu (Pustu), (2) petugas loket pendaftaran yang kurang ramah dan sopan terhadap karyawan, (3) terbatasnya jam efektif pelayanan karyawan yang masih dibawah pukul 12.30. (4) obat yang diberikan terkesan obat generik dan bahkan (5) Petugas Puskesmas yang sudah menutup loket pendaftaran pada saat jam kerja. Masalah lain yang ditemukan pada Puskesmas Kalasan Sleman adalah seiring terjadinya kenaikan biaya retribusi yang diberlakukan oleh Pemerintah Kabupaten Sleman sejak awal Januari 2013 dari Rp 3,500,- menjadi Rp 5.000,bagi warga ber-KTP Sleman.

Kondisi ini menimbulkan dampak bagi penyelenggaraan pelayanan kesehatan di Puskesmas Kalasan, yang harus diakui bahwa sistem pelayanannya masih belum sebagus pelayanan kesehatan dari pihak swasta karena perbedaan orientasi, visi dan misinya. Orientasi pelayanan 
kesehatan swasta yang bersifat profit, memberikan kontribusi yang memuaskan kepada karyawan dan keluarganya. Kecepatan dalam pelayanan, mutu layanan yang memuaskan pengguna dan keluarga dan ketepatan diagnosis penyakit serta besarnya biaya yang meyakinkan pengguna, menjadi pesaing berat bagi sistem pelayanan Puskesmas yang orientasinya pada pelayanan masyarakat umum.

Upaya mengatasi berbagai keluhan mengenai perlunya peningkatan kualitas pelayanan kesehatan yang diberikan oleh puskesmas-puskesmas yang berada dibawah naungan dan tanggung jawab Dinas Kesehatan Kabupaten Sleman, mendorong Pemerintah Kabupaten Sleman untuk menerapkan ISO 9001: 2008 sebagai standar baku pengukuran kualitas pelayanan kesehatan oleh institusi Puskesmas. Standarisasi kualitas pelayanan ISO 9001: 2008 sangat penting dalam rangka percepatan terwujudnya kualitas pelayanan kesehatan dasar oleh Puskesmas yang bermutu, adil dan merata sebagaimana yang diamanatkan dalam Visi Indonesia Sehat 2010. Pemberlakuan standarisasi mutu pelayanan kesehatan yang tertuang dalam ISO 9001: 2008 di Puskesmas Kalasan secara efektif mulai diberlakukan tanggal 09 Juli 2009, sehingga memasuki periode tahun anggaran 2013/2014 ini dapat dikatakan mulai memasuki tahun ke-4. Oleh sebab itu, diharapkan pemberlakuan standarisasi mutu pelayanan kesehatan dasar oleh Puskesmas tersebut dapat meningkatkan kualitas pelayanan kesehatan sebagaimana vang diamanatkan oleh undang-undang yaitu mewujudkan kualitas pelayanan kesehatan dasar yang bermutu, adil dan merata sebagai salah satu aspek penting terwujudnya kualitas SDM masyarakat Indonesia yang berkualitas dan berdaya saing global.

\section{METODE PENELITIAN}

Penelitian ini dirancang sebagai penelitian survey yang menjelaskan fenomena (crosscectional survey), sehingga penelitian ini termasuk penelitian kuantitatif. Tujuannya untuk menjelaskan suatu keadaan yang terjadi ketika penelitian dilakukan dan dirancang untuk menentukan besaran hubungan atau pengaruh variabel dengan variabel yang lain (Djarwanto. 2006). Variabel yang hendak dijelaskan dalam penelitian ini adalah kualitas pelayanan puskesmas Kalasan Kabupaten Sleman, variabel yang menjelaskan adalah sertifikasi
ISO 9001:2008 puskesmas Kalasan Kabupaten Sleman.

Penelitian ini dilakukan di Puskesmas Kalasan Kabupaten Sleman Pertimbangan memilih Puskesmas Kalasan Kabupaten Sleman, adalah; Terdapat masalah mengenai sertifikasi ISO 9001: 2008, kepuasan kerja karyawan, lingkungan kerja dan kualitas pelayanan di Puskesmas Kalasan Kabupaten Sleman. Puskesmas Kalasan Kabupaten Sleman tersebut cukup tersedia data yang peneliti butuhkan dan data tersebut menurut peneliti dapat dipertanggungjawabkan. Belum terdapat penelitian sejenis di lokasi penelitian.

\section{Materi Penelitian}

\section{Sertifikasi ISO 9001: 2008}

ISO 9001:2008 merupakan suatu prosedur yang terdokumentasi dan praktek-praktek standar untuk manajemen sistem, yang bertujuan menjamin kesesuaian dari suatu proses dan produk (barang atau jasa) terhadap kebutuhan atau persyaratan tertentu, dimana kebutuhan atau persyaratan tertentu tersebut ditentukan dispesifikasikan oleh karyawan maupun organisasi (Cortada, 1993). Sertifikasi ISO akan mendorong institusi untuk secara efektif menerapkan dan memelihara ISO 9001 : 2008 sebagai standar manajemen yang telah dipilih. Hal tersebut dapat dirasakan dengan adanya dokumentasi-dokumentasi, alur kerja, komunikasi, job description,dan prosedur operasi standar (SOP) yang sudah terkelola dengan baik sehingga semua elemen institusi dapat memahami tugasnya masing-masing (Rivai, 2005). Indikator yang diukur adalah: (1) Manajemen mutu, (2) Realisasi pelayanan medis, (3) Pengukuran prosedur operasi standar layanan kesehatan, (4) Analisis dan perbaikan standar standar layanan kesehatan.

\section{Kepuasan kerja karyawan}

Kepuasan kerja merupakan generalisasi sikap karyawan terhadap pekerjannya yang memiliki berbagai aspek. Sikap seorang terhadap pekerjaannya mencerminkan pengalaman menyenangkan atau tidak menyenangkan serta harapan-harapannya di masa depan (Horald E. Bart (1997).

Karyawan dipuaskan dengan suatu aspek khusus dari pekerjaan mereka (rekan kerja, atasan, prestasi, 
upah dan lain-lain). Hasil pekerjaan yang secara keseluruhan memuaskan kebutuhannya, yakni tercapainya harapan dan keinginan (perasaan) terhadap hasil pekerjaan (Ahwari, 2007). Indikator kepuasan kerja meliputi: Gaji, Promosi, Kompensasi, Komunikasi, Fasilitas.

\section{Lingkungan kerja}

Lingkungan kerja menurut Ahwari (2007), adalah segala sesuatu yang ada di sekitar pekerjaan dan dapat mempengaruhi dirinya dalam menjalankan tugas-tugas atau aktivitas dalam bekerja. Ukuranukuran suasana kerja secara kualitatif dan kuantitatif harus datang dari pegawai dan manfaatnya bergantung pada kesediaan pegawai untuk membagi perasaan mereka yang sesungguhnya, bila pegawai merasa bahwa pimpinan menghargai dan menerima saransaran mereka, misalnya keseragaman standart dan penghasilan.

Indikator lingkungan kerja, dalam hal ini meliputi: (1) Penataan ruang kerja dan sirkulasi udara, (2) keselamatan kerja, (3) hubungan dan kerjasama antara karyawan, (4) penataan peralatan, (5) fasilitas ruangan ibadah dan kamar mandi.

\section{Kualitas pelayanan}

Kualitas pelayanan merupakan awal yang terdiri dari langkah-langkah menetapkan sasaran pelayanan, penetapan kegiatan yang perlu untuk mencapai sasaran pelayanan yang bermutu. Penyediaan sumber daya yang dibutuhkan untuk pelayanan yang bermutu, menetapkan ukuran kinerja yang bermutu, penelaahan kinerja atas dasar sasaran, penetapan pemberian imbalan yang berdasarkan hasil Kotler (2001). Indikator kualitas pelayanan antara lain: keandalan (reliability), ketanggapan responsiveness), ketulusan (empathy), kepastian (assurance) dan keberwujudan (tangible).

Cara pengukuran yang dipakai untuk keempat variabel tersebut dengan skala Lickert (Azwar, 2004), terdiri empat pilihan jawaban dengan skala satu sampai empat, dengan jawaban skor tinggi atau skor rendah. Alternatif jawaban netral dihindari agar diperoleh kejelasan persepsi ataupun sikap responden.. Adapun deskripsi skor sebagai berikut: (1) Sangat setuju di skor 4. (2) Setuju diberi skor 3, (3) Tidak setuju di skor 2, (4) Sangat Tidak setuju diberi skor 1.

\section{Teknik Pengumpulan Data}

Teknik pengumpulan data dengan melakukan penelitian lapangan, yakni peneliti mengamati secara langsung objek yang diteliti dan melakukan pencatatan secara sistimatik (Moleong, 2006). Penelitian ini menggunakan teknik kuesioner sebagai sumber data primer dan teknik studi dokumentasi sebagai sumber data sekunder.

\section{Teknik Angket}

Menurut Arikunto (2006) angket yang digunakan dalam penelitian ini terdiri dari item pertanyaan yang disusun berdasar indikator variabel penelitian dengan cara modifikasi dengan angket yang pernah digunakan untuk variabel yang sama atau hampir sama yang terdapat dalam penelitian terdahulu.

\section{Studi dokumentasi}

Menurut Suharsimi Arikunto (2006) dalam teknik dokumentasi ini, data yang dikumpulkan adalah data hasil catatan manajemen Puskesmas Kalasan Kabupaten Sleman mengenai (1) Sertifikasi ISO 9001:2008, (2) kualitas pelayanan Puskesmas Kalasan Kabupaten Sleman.

\section{Uji Prasarat Analisis}

\section{Uji Validitas dan Reliabilitas}

Pengukuran Validitas dan reliabilitas dengan mengambil secara acak (random) terhadap responden yang ditentukan secara proporsional (antara 20-30 responden) sesuai bagiannya pada Puskesmas Kalasan Kabupaten Sleman.

\section{Uji Validitas}

Uji validitas digunakan untuk menunjukkan tingkat keabsahan suatu instrumentyakni angket sebagai metode utama untuk memperoleh kelengkapan data, angket diberikan skor berdasarkan skala Likert. Suatu alat ukur dikatakan valid, apabila alat tersebut 
benar mengukur apa yang harus diukur. Memakai teknik korelasi product moment dari Pearson (Azwar, 2004). Berdasarkan ketentuan, apabila rhitung $>$ rtabel maka dikatakan valid. Uji validitas dinyatakan secara empiris dengan corrected item total correlation berdasarkan analisis kesahihan butir angket. Teknik korelasi product moment yang kriteria pengukurannya yaitu $\mathrm{p}$ value $<0.05$ maka pernyataan tersebut dinyatakan valid.

\section{Uji Reliabilitas}

Reliabilitas alat ukur merupakan konsistensi hasil pengukuran bila alat tersebut digunakan orang yang sama pada waktu yang berbeda (Azwar, 2004). Penelitian ini, reliabilitas yang dipakai adalah reliabilitas internal yang diperoleh dengan menganalisis data dari satu kali hasil pengetesan. Metode ini menggunakan Cronbrach Alpha. Instrumen dikatakan reliabel apabila Cronbrach Alpha $>0,60$.

\section{Analisis Data}

Untuk memperoleh kesimpulan dalam penelitian ini, dilakukan analisis terhadap Sertifikasi ISO 9001:2008, kepuasan kerja karyawan, lingkungan kerja yang dijadikan tolok ukur kualitas pelayanan Puskesmas Kalasan Kabupaten Sleman. Alat analisis yang digunakan dalam penelitian ini adalah secara deskripti

\section{HASIL DAN PEMBAHASAN}

\section{Hasil Uji Validitas dan Reliabilitas}

\section{Hasil Uji Validitas}

Hasil uji validitas angket mengenai Sertifikasi ISO 9001: 2008 sebanyak 10 butir pernyataan dan terdapat 1 pernyataan yang tidak valid, yaitu pernyataan nomor 9 . Sebanyak 9 pernyataan dinyatakan valid dan digunakan untuk mendapatkan data primer penelitian ini. Hasil uji validitas Kepuasan Kerja Karyawan sebanyak 10 butir pernyataan dan terdapat 2 pernyataan yang tidak valid, yaitu pernyataan nomor 3 dan nomor 8 . Tidak diganti karena tidak mengurangi validitas angket penelitian yang digunakan. Hasil uji validitas angket lingkungan kerja sebanyak 10 butir pernyataan dan terdapat 1 pernyataan yang tidak valid, yaitu pernyataan nomor 4 tidak diperbaiki lagi. Kualitas Pelayanan Puskesmas sebanyak 10 butir pernyataan dan terdapat 1 pernyataan yang tidak valid, yaitu pernyataan nomor 3 tidak diperbaiki lagi, tidak mengurangi validitas angket penelitian yang digunakan.

\section{Hasil Uji Reliabilitas}

Hasil uji reliabilitas instrument mengenai hasil nilai untuk Pelaksanaan Sertifikasi ISO 9001: 2008 diperoleh nilai sebesar $0,943>0,312$ maka instrument Pelaksanaan Sertifikasi ISO 9001: 2008 dinyatakan reliabel. Sub-variabel Kepuasan Kerja Karyawan diperoleh nilai sebesar 0,894 > 0,312 maka dinyatakan reliabel. Sub-variabel Lingkungan kerja diperoleh nilai sebesar $0,881>0,312$ instrument sub-variabel Lingkungan kerja dinyatakan reliabel. Hasil nilai untuk pelayanan Puskesmas Kalasan diperoleh nilai sebesar $0,943>0,312$ maka instrument sub-variabel pelayanan Puskesmas Kalasan dinyatakan reliabel.

\section{Pembahasan}

\section{Variabel Pelaksanaan Sertifikasi ISO 9001: 2008}

Temuan minor terjadi bila organisasi tidak konsisten dalam menjalankan sistem atau hanya sebagian persyaratan yang diterapkan dari yang seharusnya. Mengenai ketrampilan yang dimiliki petugas perlu motivasi pimpinan Puskesmas Kalasan agar makin ditingkatkan berdasar standar layanan. Tendensi dari temuan minor bahwa Pimpinan Puskesmas Kalasan menghendaki karyawan hati-hati dan cermat dalam menentukan anamnesia terhadap pasien.

\section{Sub-variabel Kepuasan Kerja Karyawan}

Kepuasan kerja karyawan adalah suatu keadaan aktifitas yang menyangkut fisik, psikis dan sosial yang membuat individu mempunyai sikap mentaati peraturan dengan penuh kesadaran dan tanggung jawab, identifikasi personal terhadap upaya pencapaian tujuan puskesmas sesuai keahliannya sehingga meningkatkan efektititas perusahan dan disertai pengabdian yang kuat. 


\section{Sub-variabel lingkungan kerja}

Setiap karyawan diberikan perlindungan terhadap resiko pekerjaan, baik berupa alat-alat kelancaran kerja maupun keamanan kerja. Hal ini terjadi manakala pimpinan Puskesmas memfasilitasi terciptanya keselamatan kerja karyawan dan pasien, dalam hubungannya dengan layanan medis. Karyawan mampu menjalin kerja sama dengan sesama karyawan, dalam melaksanakan pekerjaan. Karyawan sebagai salah satu sumber daya manusia di puskesmas merupakan profesi yang terlibat pelayanan bidang kesehatan, menjadi bagian integral dari sistem kesehatan yang dijalankan Puskesmas Kalasan Kabupaten Sleman dengan mutu pelayanannya.

\section{SIMPULAN}

Berdasar hasil analisis deskriptif dalam pelaksanaan sertifikasi ISO 9001:2008 bahwa karyawan membutuhkan pengetahuan dan ketrampilan kerja agar mampu menyelesaikan masalah dalam pekerjaan yang menjadi tanggung jawabnya. Masalah yang terkait dengan aspek kuratif ditekankan agar diberikan kepada pasien rawat jalan dan stabilisasi pasien gawat darurat dan rujukan.

Sub-variabel Kepuasan Kerja Karyawan dalam bentuk pelibatan karyawan (involvement) adalah pentingnya proses mengikutsertakan para karyawan disemua lini sehingga tujuan puskesmas sektor tertentu akan cepat tercapai. Sub-variabel lingkungan kerja karyawan dengan menjalin kerja sama dengan sesama karyawan, baik dalam melaksanakan pekerjaan, membentuk team kerja dan rasa kesejawatan yang terjaga agar tidak terjadi kesenjangan prioritas dan perhatian pimpinan unit. Hasil analisis deskriptif sub-variabel Pelayanan Puskesmas Kalasan diperoleh hasil bahwa pengalaman praktik bekerja, baik di bagian pelayanan administrasi maupun di bagian pelayanan medis yang terpadu dan menganut model pelayanan kepada klien (pasien) ditempat kerja dan lebih berfokus pada peningkatan kualitas pelayanan Puskesmas Kalasan secara tepat. Menerapkan sistim manajemen mutu berdasarkan konsep TQM pada proses produksi yang efisien sebagai upaya perkuatan daya saing sudah tidak dapat ditunda-tunda lagi.

\section{DAFTAR PUSTAKA}

1. Ahwari. Sofyan. 2007. Manajemen Personalia. Ghalia Indonesia. Jakarta.

2. Aydin W. and Ozor Dorothea W, 2005, Manajemen Kualitass : Pendekatan Sisi Kualitatif, Ghalia Indonesia, Jakarta.

3. Briscoe E. Margareth, Jerome S. Arcaro 2005, dikutip dalam http://eprints.uny.ac.id/9686/3/bab\%202.pdf, diakses 3 Mei 2014.

4. Cortada. Davis, K., \& Newstroom, J. W. 1993. Perilaku Dalam Organisasi. Jilid 1, Edisi ke-7 A. Dharma, Pengalih bahasa. Jakarta : Erlangga.

5. Dessler, G. 1997. Human Resource Management, Seventh edition, by Prentice Hall, Inc, New Jersey. B. Molan. 1997. Manajemen Sumberdaya Manusia. Prenhallindo, Jakarta.

6. Gingele, J., Childe, S.J. and Miles, M.E. 2009, "A modelling technique for reengineering business processes controlled by ISO 9001: 2008", Computers in Industry, Vol. 49.

7. ISO 9001: 2008 dikutip dalam http://eprints.uny.ac.id/9686/3/bab\%202.pdf, diakses 3 Februari 2014.

8. Locke, E. and Associates, 2006: Esensi Kepemimpinan, Empat Kunci untuk Memimpin dengan Penuh Keberhasilan. Spektrum-Mitra Utama Jakarta.

9. Mei Feng dan Danny Samson, 2006, dikutip dalmhttp://eprints.uny.ac.id/9686/3/bab\%202. pdf, diakses 3 Mei 2014.

10. Parncharoen I.M, 2005) dikutip dalam http://elearning.htp.ac.id/courses/PK210/docume $n t / P$ 4.3EVALUASIPRO GRAMKESEHATAN.pdf?cidReq=PK210,diakses 6 Mei 200

11. Paskard, T.D.S.W. 1995. TQM and Organizational Change and Development. Rockefeller College Press, New York

12. Siegal. Jean, B. and Lane Misouri. 1997. Consumer Behavior, Dryden Press, Edition-6t

13. Zulian Yamit, 2002, Manajemen Kualitas produk dan Jasa, Ekonisisa, Yogyakarta

14. Vroom, V. H., 1999, Work and Motivation, Wiley, New York 